\title{
Novel FANCA mutation in the first fully- diagnosed patient with Fanconi anemia in Polish population - case report
}

\author{
Anna Repczynska ${ }^{1 *}$ (D), Agata Pastorczak², Katarzyna Babol-Pokora², Jolanta Skalska-Sadowska ${ }^{3}$, \\ Malgorzata Drozniewska ${ }^{4}$, Wojciech Mlynarski ${ }^{2}$ and Olga Haus ${ }^{1}$
}

\begin{abstract}
Background: Fanconi anemia is a rare genetic disorder caused by mutations in genes which protein products are involved in replication, cell cycle control and DNA repair. It is characterized by congenital malformations, bone marrow failure, and high risk of cancer. The diagnosis is based on morphological and hematological abnormalities such as pancytopenia, macrocytic anaemia and progressive bone marrow failure. Genetic examination, often very complex, includes chromosomal breakage testing and mutational analysis.

Case presentation: We present a child with clinical diagnosis of Fanconi anemia. Although morphological abnormalities of skin and bones were present from birth, diagnosis was only suspected at the age of 8 . Chromosome breakage test in patient's lymphocytes showed increased level of aberrations (gaps, chromatid breaks, chromosome breaks, radial figures and rearrangements) compared to control. Next generation sequencing revealed presence of two pathogenic variants in FANCA gene, one of which was not previously reported.

Conclusions: The article provides additional supportive evidence that compound biallelic mutations of FANCA are associated with Fanconi anemia. It also illustrates the utility of combination of cytogenetic and molecular tests, together with detailed clinical evaluation in providing accurate diagnosis of Fanconi anemia. This report, to the best of our knowledge, describes the first fully diagnosed FA patient in Polish population.
\end{abstract}

Keywords: Fanconi anemia, Pancytopenia, Chromosomal fragility, FANC genes

\section{Background}

Fanconi anaemia (FA) is genetically heterogenous disorder and the most common inherited bone marrow failure syndrome (IBMFS). The most frequent phenotypic features, present in about $75 \%$ of patients, include short stature, microcephaly, thumb and radial site of the limbs malformations, abnormal skin pigmentation, gastrointestinal and genitourinary defects. Progressive bone marrow failure occurs in the first decade of life, initially

\footnotetext{
* Correspondence: annasz@cm.umk.pl

'Department of Clinical Genetics, Collegium Medicum in Bydgoszcz, Nicolaus Copernicus University in Torun, ul. Sklodowskiej-Curie 9, 85-094 Bydgoszcz, Poland

Full list of author information is available at the end of the article
}

manifesting with leukopenia or thrombocytopenia. Acute myeloid leukemia (AML) and solid tumors of the head and neck, skin, gastrointestinal system and genitourinary system are the most common cancers occurring in patients with FA [1-3].

So far, 23 Fanconi anemia genes (FANC) have been identified: genes encoding core complex proteins - FANCA, FANCB, FANCC, FANCE, FANCF, FANCG, FANCL and $F A N C M$, genes encoding ID2 complex proteins - FANCD2 and FANCI, and downstream genes - FANCD1(BRCA2), FANCJ(BRIP1), FANCN(PALB2), FANCO(RAD51C), FANC P(SLX4), FANCQ(ERCC4), FANCR(RAD51), FANCS(BRC A1), FANCT(UBE2T), FANCU(XRXX2), FANCV(MAD2L2/

(c) The Author(s). 2020 Open Access This article is licensed under a Creative Commons Attribution 4.0 International License, which permits use, sharing, adaptation, distribution and reproduction in any medium or format, as long as you give appropriate credit to the original author(s) and the source, provide a link to the Creative Commons licence, and indicate if changes were made. The images or other third party material in this article are included in the article's Creative Commons licence, unless indicated otherwise in a credit line to the material. If material is not included in the article's Creative Commons licence and your intended use is not permitted by statutory regulation or exceeds the permitted use, you will need to obtain permission directly from the copyright holder. To view a copy of this licence, visit http://creativecommons.org/licenses/by/4.0/. The Creative Commons Public Domain Dedication waiver (http://creativecommons.org/publicdomain/zero/1.0/) applies to the data made available in this article, unless otherwise stated in a credit line to the data. 
REV7), FANCW (RFWD3) and FANCY. Protein products of FANC genes are involved in Fanconi anemia pathway, which regulates DNA damage repair systems [4].

On a cellular level, patients with FA are unable to process DNA lesions interfering with DNA replication. This results in increased sensitivity to DNA interstrand crosslink agents such as diepoxybutane or mitomycin C. Chromosomal breakage test is the gold standard for diagnosis of FA, but is not $100 \%$ specific. A few cases of Nijmegen breakage syndrome have been reported to give a false positive results, which was finally excluded by identification of the mutations in $N B N$ (NBS1) gene. Moreover, patients with cohesinopathies - Roberts syndrome (mutated in ESCO2) and Warsaw Breakage Syndrome (mutated in DDX11) may also present positive score in the chromosome breakage test. Genes associated with FA and FA-like phenotypes encode proteins participating in DNA repair. They are also part of FA/BRCA pathway [5-8].

Cytogenetic analysis of increased levels of chromosomal breaks and radial figures after exposure to Mitomycin C (MMC) or Diepoxybutane (DEB) is recommended as a first-tier step of genetic diagnosis of Fanconi anemia. This test, although not specific for FA only, allows to differentiate FA from other chromosomal instability syndromes, such as Nijmegen syndrome, Roberts syndrome, and the Warsaw Breakage syndrome.

For molecular identification of a causative mutation confirming Fanconi anemia diagnosis, next generation sequencing (NGS) is particularly recommended.

FANCA gene (OMIM: 607139) is located on chromosome 16, band q24.3. The NM_000135.4 transcript consists of 43 exons [9]. Alterations of this gene are the most frequently observed gene changes in FA patients, contributing to over $60 \%$ of all FA cases [10, 11], making FA-A complementation group the most frequent in majority of countries [12]. High incidence of FA in ethnic-specific groups results from the founder effects associated with particular mutations [12].

The presence of the founder mutations in the specific FANC genes, which are common in some populations, allow to use targeted genetic tests. This applies, for example, to the Ashkenazi Jewish population with specific mutations in the FANCC (c.456 + 4A > T (IVS4) and FANCD1 (c.6174delT) genes, or the Japanese population with other specific mutations: in the FANCA (c.2546delC or c.3720_3724del), FANCC (c.456 + 4A > T) and FANCG (c.307 + 1G >C or c.1066C > T) genes [13]. No data on the frequency of individual, recurrent mutations in FANC genes in the Polish population has been published so far.

Hematopoietic stem cell transplantation (HSCT) is the only therapy for patients with FA to cure aplastic anemia, myelodysplastic syndrome, and acute myeloid leukemia.
Since this approach is associated with early and late complications, alternative treatments are still being searched for. Gene therapy approaches aiming to correct the genetic defect in the patient's own hematopoietic stem cells remain the most promising strategy to overcome FAassociated bone marrow failure [14, 15].

Due to heterogeneous character of the FANCA gene variants (point mutations, insertions/deletions, splicing mutations, large intragenic deletions), the most appropriate diagnostic strategy should combine various methods $[9,12,16]$. This approach is also particularly important due to the fact that many patients harbor private mutations and that the FA phenotype overlaps with other syndromes [17].

\section{Case presentation}

8-year old girl was referred for genetic counseling due to hematological abnormalities and birth defects. She was the only child of non-consanguineous parents, born at term after an uneventful pregnancy. Her birth weight was 2819 g. Apgar score was 9. Dysplastic left hip was noted at birth.

Thrombocytopenia was first noted at the age of 4 . Evaluation of the patient's bone marrow trepanobioptates revealed three lineage aplasia. The examination of patient's phenotype at the genetic counseling centre identified short stature (Fig. 1a), microcephaly, low set ears, "café-au-lait" spots, and hypoplastic thumbs (Fig. 1b). There was no intellectual disability.

\section{Methods}

\section{Chromosomal breakage test}

Cytogenetic studies were carried out on peripheral blood lymphocytes from parallel cultures without MMC and supplemented with MMC (50 nM, $150 \mathrm{nM}$ and $300 \mathrm{nM})$. Chromosome instability data were analyzed and calculated (number of metaphases with breakage, mean chromosome breakage number per aberrant metaphase, and tri-, tetra- and multi- radials frequency) [5, 18]. A healthy control was assured.

\section{Molecular testing}

Genomic DNA for molecular testing was extracted from peripheral blood using QIAmp DNA Mini Kit 50.

Array comparative genomic hybridization (aCGH) was performed using $8 \times 60 \mathrm{~K}$ Agilent SurePrint platform according to manufacturer's protocol. The results were analyzed with Cytogenomics v.5.0 software.

Next generation sequencing (NGS) was carried out with TruSightOne Sequencing Panel, on NextSeq550 machine, Illumina in the process of $300 \mathrm{bp}$ paired-end run using Mid Output Kit (Illumina). The data analyses of the target regions were performed using BurrowsWheeler Aligner Genome Alignment Software and the 


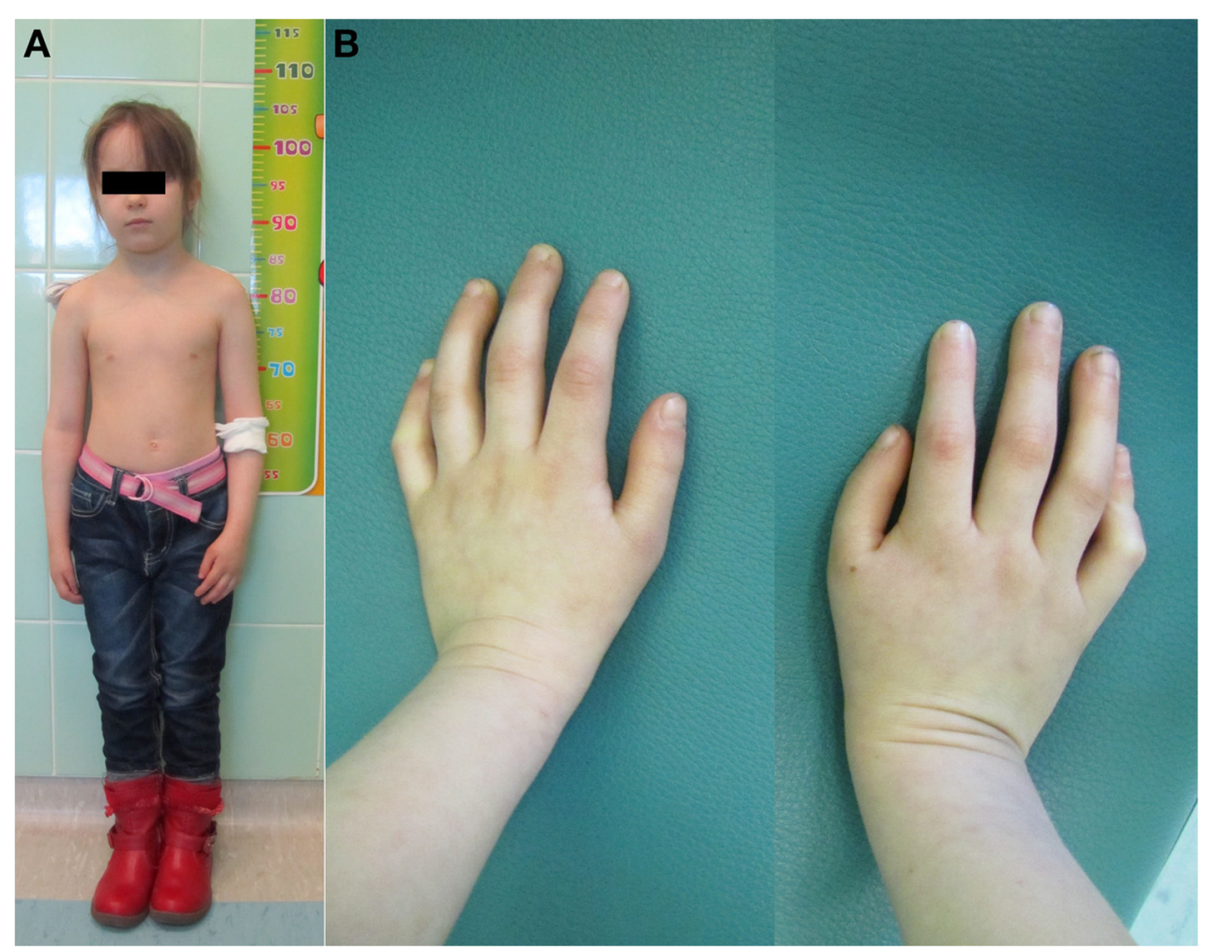

Fig. 1 Clinical features of the patient. a Patient at the age of 8 - visible short stature. b Hypoplastic and abnormally set thumbs

GATK Variant Caller algorithms and mapped to the human genome reference sequence GRCh37/hg19 [19]. The mean region coverage depth was 126 . The results were analyzed using Variant Studio v. 3.0 (Illumina) and Integrative Genomics Viewer v.2.3 [20]. The analysis focused on the following genes: FANCA, FANCB, FANCC, BRCA2, FANCD2, FANCE, FANCF, FANCG, FANCI, BRIP1, FANCL, FANCM, PALB2, RAD51C, SLX4, ERCC4, $R A D 51$ and $B R C A 1$. The filtering criteria included coverage with at least 20 reads and a minor allele frequency (MAF) below 0.01 in 1000 Genomes and ExAC databases. The pathogenicity of the revealed changes was estimated based on standard bioinformatics tools, such as: Mutation Taster, SIFT and PolyPhen-2 and using several databases, such as ClinVar, HGMD and OMIM [21-23]. An internal database was also searched for the recurrent variants.

For verification of the variants detected in NGS we used Sanger sequencing. Standard PCR conditions were used (Supplementary Table 1) with the primers specifically designed to analyze certain mutations using NetPrimer software (Supplementary Table 2). Products were sequenced on ABI3130 4-capillary sequencer (Thermo Fisher Scientific) and the results were analyzed using Sequencher v. 5.0. (Supplementary Fig. 1).

Parental molecular follow-up studies were not performed as the patient's parents did not consent to testing.

\section{Results}

Cytogenetic GTG analysis revealed normal female karyotype. Spontaneous fragility was found in $10 \%$ of the analyzed metaphases, most frequently in chromosomes 1, 4, 6, 7, 20, 21, and X (Fig. 2 a and b).

Chromosomal breakage test revealed high level of aberrations (Fig. 3 a and 3B) in patient's lymphocytes (Fig. $3 \mathrm{c}$ ) compared to healthy control (Fig. $3 \mathrm{~d}$ ).

Microarray analysis detected a female profile with no copy number imbalances that could be considered to be clinically significant.

NGS revealed presence of two pathogenic variants of the FANCA gene: NM_000135.4:c.627G>A, NP_000126 .2:p.Trp209* and NM_000135.4:c.3788_3790del, NP_ 000126.2:p.Phe1263del (Fig. 4a and b, respectively). No variants of clinical significance were detected in other FANC genes.

As the parental samples have not been tested, the mode of inheritance could not have been determined.

\section{Discussion and conclusions}

Fanconi anemia is a complex and heterogeneous disorder and the most common inherited bone marrow failure syndrome [10]. Patients struggle with progressive bone marrow failure and severe hematological complications [24]. In addition, congenital malformations are also present $[25,26]$. 

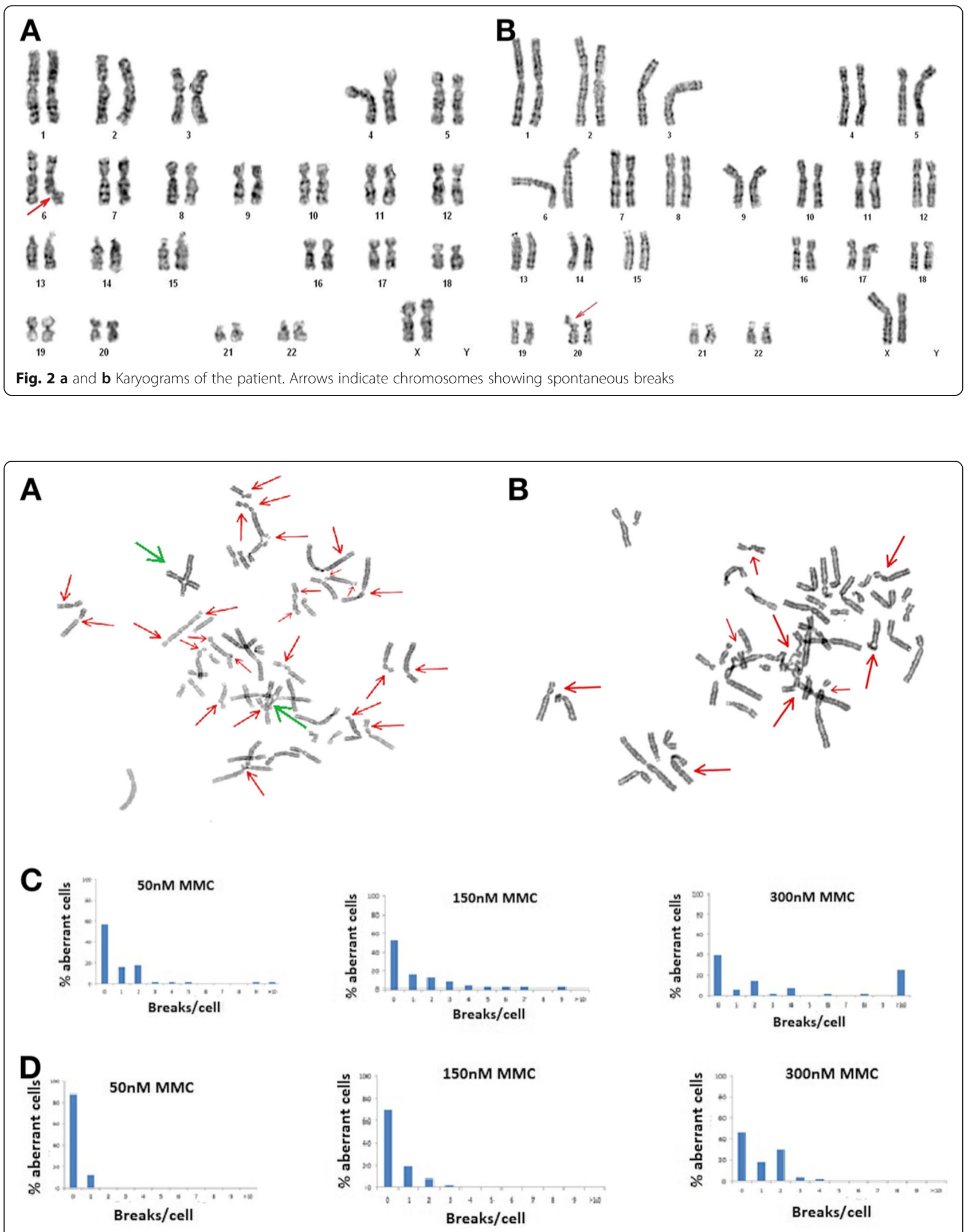

Fig. 3 a and $\mathbf{b}$ Metaphase spreads in MMC test. Red arrows show gaps, chromatid breaks (chtb) and acentric fragments (ace). Green arrows show radial figures. $\mathbf{c}$ Results of chromosomal breakage MMC test in the patient. $\mathbf{d}$ Results of chromosomal breakage MMC test in healthy control 

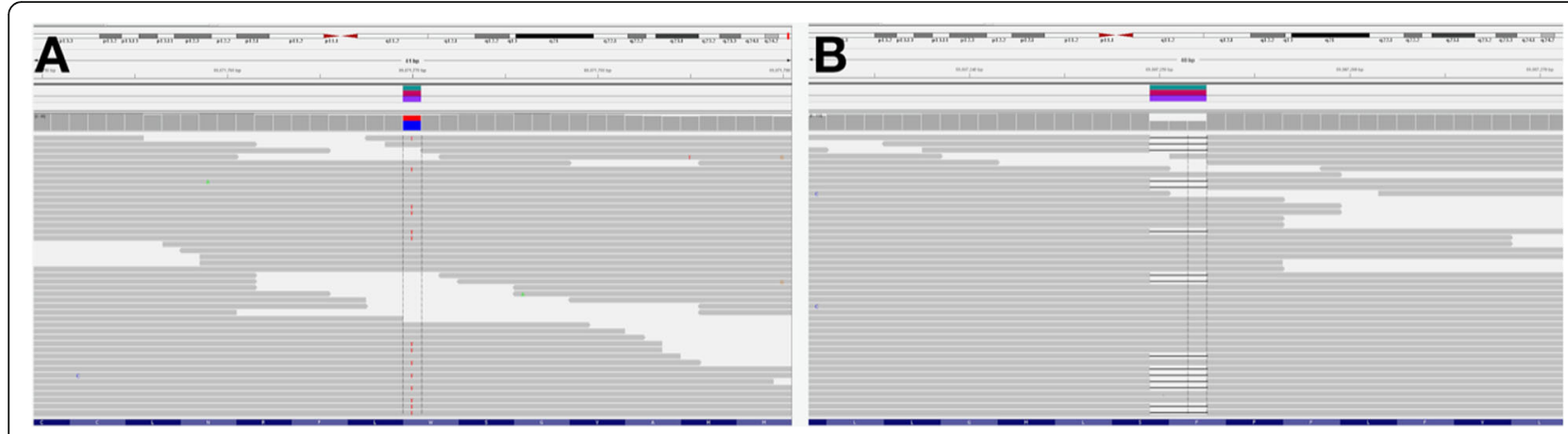

Fig. 4 Visualization of FANCA sequencing reads showing c.627G>A (a), and c.3788_3790del (b)

The c.3788_3790del (p.Phe1263del) mutation, one of the mutations present in our patient, has been reported as the most frequent FA mutation worldwide. Castella et al. (2011) suggested that this results from founder character of the mutation (a common Indo-European ancestor) [12]. There are 287 entries for this mutation in the Leiden Open Variation Database [as of 21.02.2020]. All of these have been reported as germline mutations, resulting in an in-frame deletion of phenylalanine at a position that is conserved across species. This particular mutation has been reported as homozygous or compound heterozygous with other pathogenic variants in numerous FA patients [27-29]. Experimental studies have shown that this sequence change alters nuclear localization of FANCA protein and impairs the function of FANCA in vitro, and therefore this variant has been classified as pathogenic [12].

The second mutation found in our patient, c.627G $>\mathrm{A}$ (p.Trp209*), has not been reported before. It has neither been found on ExAC nor 1000G. It suggests that this particular mutation is a private one for our patient.

Fanconi anemia presents with wide spectrum of phenotypes, affecting multiple systems [30]. Although some features, including short stature, café au lait spots are common in the majority of the patients, it is difficult to establish a 'typical' phenotype for FA. It has been reported that classical and most frequently occurring congenital abnormalities are consistent with those seen in the VACTERL-H association (V - vertebral, A - anal, $\mathrm{C}$ - cardiac, $\mathrm{T}$ - tracheo-esophageal fistula, $\mathrm{E}$ esophageal atresia, $\mathrm{R}$ - renal, $\mathrm{L}$ - upper limb and $\mathrm{H}$ - hydrocephalus) [30, 31]. The association is defined based on harboring at least three of the anomalies mentioned above [26]. Recently, Fiesco-Roa et al. described other abnormalities common in FA patients, but not included in the VACTERL-H. They have been grouped as PHENOS ( $\mathrm{P}$ - pigmentation, $\mathrm{H}$ - small head, E - small eyes, $\mathrm{N}$ - nervous system, $\mathrm{O}$ - otology, S - short stature). According to this study, patients with FA with VACTERL-H characteristics also revealed at least four out of six PHENOS features [30]. The patient reported by us had only a couple of phenotypic features of FA - short stature and hypoplastic and abnormally set thumbs. Her intellectual level was normal. However, she fits into the spectrum of FA phenotypes. There is an important phenotypic heterogeneity in this disease.

Steinberg-Shemer et al. (2019) analyzed FANC genes by Sanger sequencing in 94 FA patients in order to find a genotype-phenotype correlation. They reported no association between the affected FA gene and survival. No specific gene has been reported in association with bone marrow failure. Patients with FANCD1 and FANCJ mutations were significantly shorter compared to others. Downstream genes mutations were found to be more frequent in patients with skull, central nervous system and genitourinary anomalies, in comparison to patients with core complex genes mutations [32].

It has also been reported that patients with FANCA mutations developed MDS/leukemia at a significantly older age opposed to non-FANCA mutations patients. The authors also report on significant correlation between FANCA mutation type and congenital anomalies: short stature was present more often in patients with deletions than with nonsense mutations. Splice-site mutations positively correlated with developmental delay and central nervous system anomalies, whereas missense mutations were present less often in association with congenital heart disease [32].

Genetic study should be performed, if possible, in all patients with FA suspicion, their siblings and parents. It is important to stress that identification of FANC gene causative mutations in any clinically suspected child not only supports clinical diagnosis enabling appropriate treatment, including less genotoxic medical procedures, and mild conditioning regimens before HSCT, but also allows appropriate genetic counseling for the whole family. It also facilitates accurate and targeted molecular studies, i.e. by noninvasive prenatal diagnosis (NIPD). 
The parents of our patient were not tested, therefore their carrier status, if any, is unknown.

Their genetic risk of having future children with FA is $25 \%$, under the assumption that each of them is a heterozygous carrier of one of the mutations found in their daughter. Therefore, a prenatal diagnosis should be offered to the mother of our patient at each subsequent pregnancy.

\section{Supplementary information}

Supplementary information accompanies this paper at https://doi.org/10. 1186/s13039-020-00503-4.

Additional file 1: Figure S1. Sanger sequencing chromatograms showing the FANCA mutations detected in the reported patient: c.627G > A (A) and C.3788_3790del (B).

Additional file 2: Table S1. The sequences of primers used for verification of pathogenic FANCA variants detected in the reported patient using Sanger sequencing.

Additional file 3: Table S2. Characteristics of the pathogenic FANCA variants identified in the reported patient.

\section{Abbreviations}

IBMFS: Inherited Bone Marrow Failure Syndrome; AML: Acute Myeloid Leukemia; MMC: Mitomycin C; FA: Fanconi Anemia; DEB: Diepoxybutane; NGS: Next Generation Sequencing; HSCT: Hematopoietic Stem Cell Transplantation; aCGH: Array Comparative Genomic Hybridisation; VACTERL$\mathrm{H}$ : Association of features including Vertebral, Anal, Cardiac, Tracheoesophageal fistula, Esophageal atresia, Renal, upper Limb and Hydrocephalus; PHENOS: Association of abnormalities including Pigmentation, small Head, small Eyes, Nervous system, Otology, Short stature

\section{Acknowledgements}

The authors would like to thank the family for their participation in the study and consent to publish the data.

\section{Authors' contributions}

$[\mathrm{AR}]$ and $[\mathrm{OH}]$ made substantial contribution to conception and design of the study, analysis and interpretation of data, and manuscript preparation. $[\mathrm{OH}]$ supervised the study. [AP], [KB-P], [JS-S] and [WM] made substantial contribution to analysis and interpretation of data. [AP] and $[\mathrm{OH}]$ made substantial contribution to data acquisition. [MD] contributed to analysis and interpretation of data, and manuscript preparation. All authors were involved in revising the manuscript critically for important intellectual content. The authors read and accepted the final manuscript. The author(s) read and approved the final manuscript.

\section{Funding}

None to report.

\section{Availability of data and materials}

Complete datasets used and analysed during the current study are available from the corresponding author on reasonable request.

\section{Ethics approval and consent to participate}

The study was performed in accordance with the Declaration of Helsinki and accepted standards of ethics. The patient's parents signed written informed consent for the participation in the study.

\section{Consent for publication}

The patient's parents signed written informed consent for the publication of the clinical data, and images.

\section{Competing interests}

The authors declare that they have no competing interests.

\section{Author details}

'Department of Clinical Genetics, Collegium Medicum in Bydgoszcz, Nicolaus Copernicus University in Torun, ul. Sklodowskiej-Curie 9, 85-094 Bydgoszcz, Poland. ${ }^{2}$ Laboratory of Immunopathology and Genetics, Department of Pediatrics, Oncology and Hematology, Medical University of Lodz, ul. Sporna 36/50, 91-738 Lodz, Poland. Department of Oncology, Hematology and Pediatric Transplantology, Medical University in Poznan, ul. Szpitalna 27/33, 60-572 Poznan, Poland. ${ }^{4}$ West Midlands Regional Genetics Laboratory, Birmingham Women's and Children's Hospital NHS Foundation Trust, Mindelsohn Way, B15 2TG Birmingham, UK.

Received: 23 April 2020 Accepted: 16 July 2020

Published online: 10 August 2020

\section{References}

1. Dokal I. Inherited bone marrow failure syndromes. J Hematop. 2011;4:53-60.

2. Savage SA, Walsh MF. Myelodysplastic syndrome, acute myeloid leukemia, and cancer surveillance in Fanconi anemia. Hematol Oncol Clin N Am. 2018; 32:657-68.

3. Bogliolo M, Surralles J. Fanconi anemia: a model disease for studies on human genetics and advanced therapeutics. Curr Opin Genet Dev. 2015;33: 32-40.

4. Niraj J, Färkkilä A, D'Andrea AD. The Fanconi anemia pathway in cancer. Annu Rev Cancer Biol. 2019:3:457-78.

5. Oostra A, Nieuwint A, Joenje H, Winter J. Diagnosis of Fanconi anemia: chromosomal breakage analysis. Anemia. 2012;6:1-9.

6. Freire BL, Homma TK, Funari MFA, Lerario AM, Leal AM, Velloso EDRP, et al. Homozygous loss of function BRCA1 variant causing a Fanconi-anemia-like phenotype, a clinical report and review of previous patients. Eur J Med Genet. 2017;61:130-3.

7. Maung KZY, Leo PJ, Bassal M, Casolari DA, Gray JX, Bray SC, et al. Rare variants in Fanconi anemia genes are enriched in acute myeloid leukemia. Blood Cancer J. 2018:8:1-5.

8. New HV, Cale CM, Tischkowitz M, Jones A, Telfer $P$, Veys $P$, et al. Nijmegen breakage syndrome diagnosed as Fanconi anaemia. Pediatr Blood Cancer. 2005;44:494-9.

9. Li N, Song A, Ding L, Zhu H, Li G, Miao Y, et al. Novel variations of FANCA gene provokes Fanconi anemia: molecular diagnosis in a special Chinese family. J Pediatr Hematol Oncol. 2018:40:299-304.

10. Nie D, Cao P, Wang F, Zhang J, Liu M, Zhang W, et al. Analysis of overlapping heterozygous novel submicroscopic CNVs and FANCA-VPS9D1 fusion transcripts in a Fanconi anemia patient. J Hum Genet. 2019;64:899909.

11. Ben Haj Ali A, Amouri A, Sayeb M, Makni S, Hammami W, Naouali CH, et al. Cytogenetic and molecular diagnosis of Fanconi anemia revealed two hidden phenotypes: disorder of sex development and cerebro-oculo-facioskeletal syndrome. Mol Genet Genomic Med. 2019;7:1-9.

12. Castella M, Pujol R, Callen E, Trujillo JP, Casado JA, Gille H, et al. Origin, functional role, and clinical impact of Fanconi anemia FANCA mutations. Blood. 2011;117:3759-69.

13. Selenti N, Kattamis A, Kanavakis E, Kitsiou S, Mavrou A. Genetic diagnosis of Fanconi anemia. J Hematol Blood Transfus Disord. 2015:1:1-7.

14. Rio P, Navarro S, Bueren JA. Advances in the gene therapy for Fanconi anemia. Hum Gene Ther. 2018;29:1114-23.

15. Adair JE, Sevilla J, Heredia CD, Becker PS, Kiem HP, Bueren J. Lessons learned from two decades of clinical trial experience in gene therapy for Fanconi anemia. Curr Gene Ther. 2017;16:338-48.

16. Chandrasekharappa SC, Lach FP, Kimble DC, Kamat A, Teer JK, Donovan FX, et al. Massively parallel sequencing, aCGH, and RNA-Seq technologies provide a comprehensive molecular diagnosis of Fanconi anemia. Blood. 2013;121:138-48.

17. Pilonetto DV, Pereira NF, Bonfim CMS, Ribeiro LL, Bitencourt MA, Kerkhoven $\mathrm{L}$, et al. A strategy for molecular diagnostics of Fanconi anemia in Brasilian patients. Mol Genet Genomic Med. 2017;5:360-72.

18. Auerbach A. Diagnosis of Fanconi anemia by diepoxybutane analysis. Curr Protoc Hum Genet. 2016;85:8.7.1-8.7.17.

19. Li H, Durbin R. Fast and accurate long-read alignment with burrowswheeler transform. Bioinformatics. 2010;26:589-95.

20. Robinson JT, Thorvaldsdottir H, Winckler W, Guttman M, Lander ES, Getz G, et al. Integrative genomics viewer. Nat Biotechnol. 2011;29:24-6. 
21. Landrum MJ, Lee JM, Benson M, Brown G, Chao C, Chitipiralla S, et al. ClinVar: public archive of interpretations of clinically relevant variants. Nucleic Acids Res. 2016;44:D862-8.

22. McKusick VA. Mendelian inheritance in man and its online version, OMIM. Am J Hum Genet. 2007:80:588-604.

23. Stenson PD, Mort M, Ball EV, Shaw K, Phillips AD, Cooper DN. The human gene mutation database: building a comprehensive mutation repository for clinical and molecular genetics, diagnostic testing and personalized genomic medicine. Hum Genet. 2014;133:1-9.

24. Degan P, Cappelli E, Regis S, Ravera S. New insights and perspectives in Fanconi anemia research. Trends Mol Med. 2019;25:167-70.

25. Zareifar S, Dastooz H, Shahriari M, Faghihi MA, Shekarkhar G, Bordbar M, et al. A novel frame-shift deletion in FANCF gene causing autosomal recessive Fanconi anemia: a case report. BMC Med Genet. 2019;20:1-7.

26. Dimishkowska M, Kotori VM, Gucev Z, Kocheva S, Polenakovic M, PlaseskaKaranfilska D. Novel founder mutation in FANCA gene (c.3446_ 3449dupCCCT) among Romani patients from the Balkan region. Balkan Med J. 2018;35:108-11.

27. Levran O, Diotti R, Pujara K, Batish SD, Hanenberg H, Auerbach AD. Spectrum of sequence variations in the FANCA gene: an international Fanconi anemia registry (IFAR) study. Hum Mutat. 2005;25:142-9.

28. Tsangaris E, Klaassen R, Fernandez CV, Yanofsky R, Shereck E, Champagne J, et al. Genetic analysis of inherited bone marrow failure syndromes from one perspective, comprehensive and population-based cohort and identification of novel mutations. J Med Genet. 2011;48:618-28.

29. Rodriguez DEA, Lima CSP, Lourenco GJ, Figueiredo ME, Carneiro JDA, Tone $L G$, et al. Molecular analysis of the most prevalent mutations of the FANCA and FANCC genes in Brasilian patients with Fanconi anemia. Genet Mol Biol. 2005;28:205-9.

30. Fiesco-Roa MO, Giri N, McReynolds $\sqcup$, Best AF, Alter P. Genotype-phenotype associations in Fanconi anemia: a literature review. Blood Rev. 2019;37:1-8.

31. Mori M, Hira A, Yoshida K, Muramatsu H, Okuno Y, Shiraishi Y, et al. Pathogenic mutations identified by a multimodality approach in 117 Japanese Fanconi anemia patients. Hematologica. 2019;104:1962-73.

32. Steinberg-Shemer O, Goldberg TA, Yacobovich J, Levin C, Koren A, RevelVilk S, et al. Characterisation and genotype-phenotype correlation of patients with Fanconi anemia in a multi-ethnic population. Haematologica. 2019;104:1-32.

\section{Publisher's Note}

Springer Nature remains neutral with regard to jurisdictional claims in published maps and institutional affiliations.

Ready to submit your research? Choose BMC and benefit from:

- fast, convenient online submission

- thorough peer review by experienced researchers in your field

- rapid publication on acceptance

- support for research data, including large and complex data types

- gold Open Access which fosters wider collaboration and increased citations

- maximum visibility for your research: over $100 \mathrm{M}$ website views per year

At $\mathrm{BMC}$, research is always in progress.

Learn more biomedcentral.com/submissions 